\title{
IJCER Material
}

\author{
Reza Alfiyantia, Sukarmin ${ }^{a, *}$ \\ ${ }^{a}$ Chemistry Department, Faculty of Mathematics and Science, Universitas Negeri Surabaya, Surabaya \\ a*Corresponding author: sukarmin@unesa.ac.id
}

Received: October 17, 2020; Accepted: November 05, 2020; Published: December 10, 2020

\begin{abstract}
In chemistry, an abstract material could be perceived by three levels of representations that are macroscopic, sub-microscopic, and symbolic. However, many students have misconceptions due to the difficulty of shifting between the three levels of representations. Misconceptions should be reduced or prevented as early as possible because it will be resistant and difficult to change. Stoichiometry tends to abstract concepts that were challenging for some students that usually lead to misconceptions. In this study, these misconceptions were detected using a four-tier diagnostic instrument and were reduced using a conceptual change text strategy. The instrument and strategy was presented in the form of software named Stoichiometry Reconstruction, which was made by PHP programming language supported by XAMPP application because it has two functions as an assessment and learning tool. Software must be said effective before it is used by the student. This study aims to know the effectiveness of software to detect and reduce misconceptions in stoichiometry material. This study used Research and Development method. The result of this study shows that software is effective to detect and reduce misconceptions. It is proved by the average percentage of misconception shift to understand the concept about $80,13 \%$, which is categorized as effective.
\end{abstract}

Keywords: Software, misconception, stoichiometry, effectiveness

\section{INTRODUCTION}

Chemistry represents an abstract material because it deals with reactions and an atomic constituent of compounds that cannot be observed [1]. It consists of three representation levels, namely macroscopic, sub-microscopic, and symbolic. The moving between macroscopic, sub-microscopic, and symbolic is very important in teaching chemistry. However, many students have misconceptions due to the difficulty in understanding the moving between the three representation levels [2]. The misconception is the viewing of a concept that is different from the expert believing. It should be reduced or prevented as early as possible because it is resistant and difficult to change [3]. There are several concepts in chemistry material that have a high percentage of misconceptions. Most concepts that have a high percentage of misconceptions are coming from stoichiometry material. The existing experiment results prove it stated that from 73 pupils of Grades XI in SMA Negeri 1 Sukoharjo have misconceptions in stoichiometry material with a percentage about $40.46 \%$ in chemical equation concept, $38.36 \%$ in relative atomic or molecular mass concept, and $53,77 \%$ in mole concept [4]. The misconception in stoichiometry concepts must be reduced because stoichiometry is the important basic concept of analytical chemistry.

Misconceptions can be detected by the diagnostic and non-diagnostic test. One example of a nondiagnostic test is the essay. This test is less effective because it needs many times [5]. Therefore the diagnostic test is believed as an effective way to detect misconceptions. There are several examples of a diagnostic test, such as two-tier diagnostic test [6], three-tier diagnostic test [7], and four-tier diagnostic test [8]. The four-tier diagnostic test represents the best instrument to detect misconceptions because it can hold all the strengths provided with a three-tier diagnostic test and truly assess misconceptions free 
of errors and lack of knowledge [9]. This instrument is the modifications of a three-tier diagnostic test. The modifications were located in the second and fourth-tiers, namely the confidence levels [10]. The test contains four tiers: questions with several options, confidence levels of the answer in the questions, reasons for the answer in the first tier, and the confidence levels of the reasons. Based on all tiers' results, the student's understanding of a concept was classified as understanding, did not understand, and misconceptions [11]. In this way, students can immediately know about their understanding of a concept to be dissatisfied with their understanding if it is classified as misconceptions or did not understand the concept. This condition is suitable to use in changing misconceptions.

According to Posner, four conditions have to create to change the misconceptions. These conditions are people must be in dissatisfaction with their existing conceptions, a new concept must be intelligible, a new concept must appear initially plausible, and a new concept should suggest the possibility of a fruitful research program. The strategy that is appropriate for cheating these conditions is the conceptual change text (CCT) strategy. CCT is a strategy for reducing misconceptions using the text to show the differences between the scientific conception and the reader's conception [12]. In this condition, cognitive conflict will happen to reconstruct the new concepts in the reader's mind.

The new concept is easier to explain if the information served in visual and verbal [13]. This statement is supported by the dual coding theory based on the Paivio. The information that is served in visual and verbal increases the usage of working memory. People will easier process new information on their mind when it is served in both visual and verbal. Basic computer multimedia such as software can present information in both visual and verbal simultaneously. The software can present pictures to help teachers in explaining the abstract concept of chemistry material. The software also has two functions as an assessment tool and learning tool. Therefore, software is suitable to detect misconception using four-tier diagnostic instruments and reduce misconceptions based on the CCT strategy.

Based on the background that has already explained, this study aims to determine the effectiveness of software to detect and reduce misconceptions on stoichiometry material. This purpose can be reached by answering the research question: "how is the effectiveness of software to detect and reduce misconceptions on stoichiometry material?".

\section{MATERIALS}

This study used the Research and Development (R\&D) method written by Sugiono [14]. There are 10 stages in this method, namely 1) potentials and problems, 2) data collection, 3) product design, 4) design validation, 5) design revision, 6) product trial, 7) product revision, 8) trial use, 9) product revision, and 10) wide production. The software named Stoichiometry Reconstruction was made PHP programming language supported by XAMPP application. It has been validated by the experts and revised based on their comments. It has been categorized as valid with a content validity percentage of $85,37 \%$ and a construct validity percentage of $76,67 \%$. Thus, this study only discussed the results of product trials at the sixth stage to determine the effectiveness of software, while the seventh to the tenth stages were not carried out.

The effectiveness of software was analyzed from the shift in student's conceptions when working on diagnostic test. The test used four-tier diagnostic test instrument, which consisted of four-tiers. The fourth tiers are concept question, believing of question answer, reason, believing of reason. The questions consisted of the definition of molar mass concept, definition and application of percent composition by mass concept, and definition and characteristics of limiting reactant concept. The result of student's answer classified as misconception (M), understand the concept $(\mathrm{U})$, or did not understand the concept (DU) based on Table 1.

TABLE 1. Four-tier diagnostic classification

\begin{tabular}{ccccc} 
Answer & Confidence & Reason & Confidence & Category \\
\hline True & Sure & True & Sure & Understand (U) \\
\hline True & Not & True & Not & Did not Understand \\
True & Sure & True & Not & (DU) \\
True & Not & True & Sure & \\
True & Not & False & Not & \\
False & Not & True & Not & \\
False & Not & False & Not & \\
\end{tabular}




\begin{tabular}{ccccc} 
Answer & Confidence & Reason & Confidence & Category \\
\hline True & Sure & False & Not & \\
False & Not & True & Sure & \\
\hline True & Not & False & Sure & Misconceptions (M) \\
True & Sure & False & Sure & \\
False & Sure & True & Not & \\
False & Sure & True & Sure & \\
False & Sure & False & Not & \\
False & Not & False & Sure & \\
False & Sure & False & Sure & \\
& & & & \\
\end{tabular}

The data collecting in this study uses four-tier diagnostic test. The test was doing twice as pretest and postest. Pretest was doing before passing the reduction part in by the software while posttest was doing after that. The pretest and post-test results were classified based on Table 1, so that we get the initial and last student's conception. The data were compared to know the conception shifts. Both the initial conception and conception shift results were analyzed. There are several conception shifts, first conception shift from misconception to understanding the concept $(\mathrm{M}-\mathrm{U})$, second from misconception to did not understand the concept (M-DU), third from did not understand the concept to misconception (DU$M$ ), and fourth from did not understand the concept to understand the concept (DU-U). M-U and DU-U represent a positive shift, while M-DU and DU-M represent a negative shift. The cognition conflict data supported the conception shift data from the student's anwer when they passed the second stage of the reduction part. In this part, student are given three questions about the cognition conflict that may be happened in their mind. The effectiveness of software is analyzed by calculating the number of $\mathrm{M}-\mathrm{U}$ then coverting it to percent using the formula below.

$$
\begin{aligned}
& \% M_{\text {shift }}=\frac{\Sigma M-U}{\Sigma M_{\text {initial }}} \times 100 \% \\
& \text { Information: } \\
& \Sigma M-U=\text { Number of } M-U \text { shift } \\
& \Sigma M \quad=\text { Number of initial misconceptions }
\end{aligned}
$$

The percentage is then interpreted based on Table 2. The software is said effective if its effectiveness percentage $\geq 61 \%[16]$.

\section{RESULT AND DISCUSSION}

This study had conducted from September 2019 to February 2020, located in SMA Negeri 1 Gedangan. The subject of this study is 15 students. These students were selected based on the results of a diagnostic test that has already done before. The diagnostic test used four-tier diagnostic test instrument. Then the results are presented in the form of percent. Students who have the highest percentage of misconception were selected as the subjects of this study.

Students have to try the software using a personal computer that has already connected to a server via school WiFi. According to their concept classification of four-tier in Table 1 after they did pretest, the software detected their initial conceptions. The pretest results on stoichiometry material can be seen in Figure 1 to Figure 3. 


\section{Molar Mass Pretest Results}

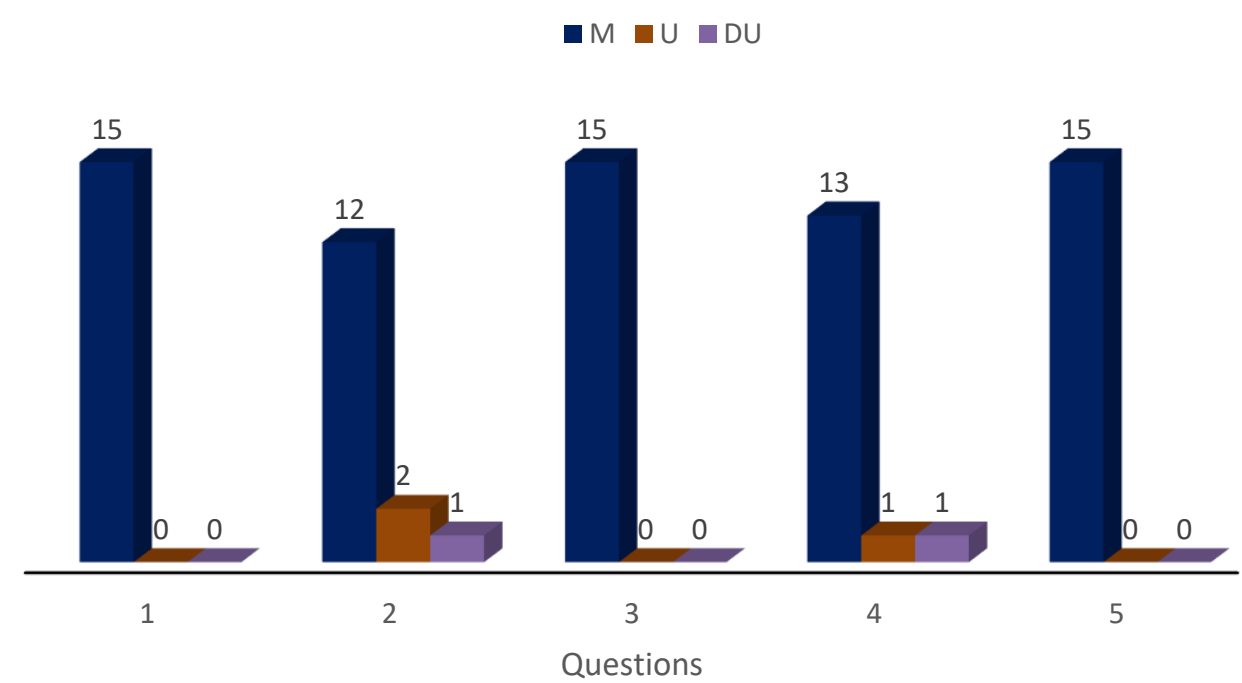

FIGURE 1. Pretest Results of Molar Mass Concept

There are 5 questions about a molar mass concept that has to answer by students in the pretest. Figure 1 shows that all of the students hold misconceptions $(M)$ in answering question number 1,3, and 5. For question number 2, there are 12 students hold misconceptions (M), 2 students have understood the concept $(\mathrm{U})$, and 1 student did not understand the concept (DU). While in question 3 , there are 13 students who hold misconceptions (M), 1 student has understood the concept (U), and 1 student did not understand the concept (DU).

\section{Percent Composition by Mass Pretest Results}

$\square \mathrm{M} \square \mathrm{U} \square \mathrm{DU}$

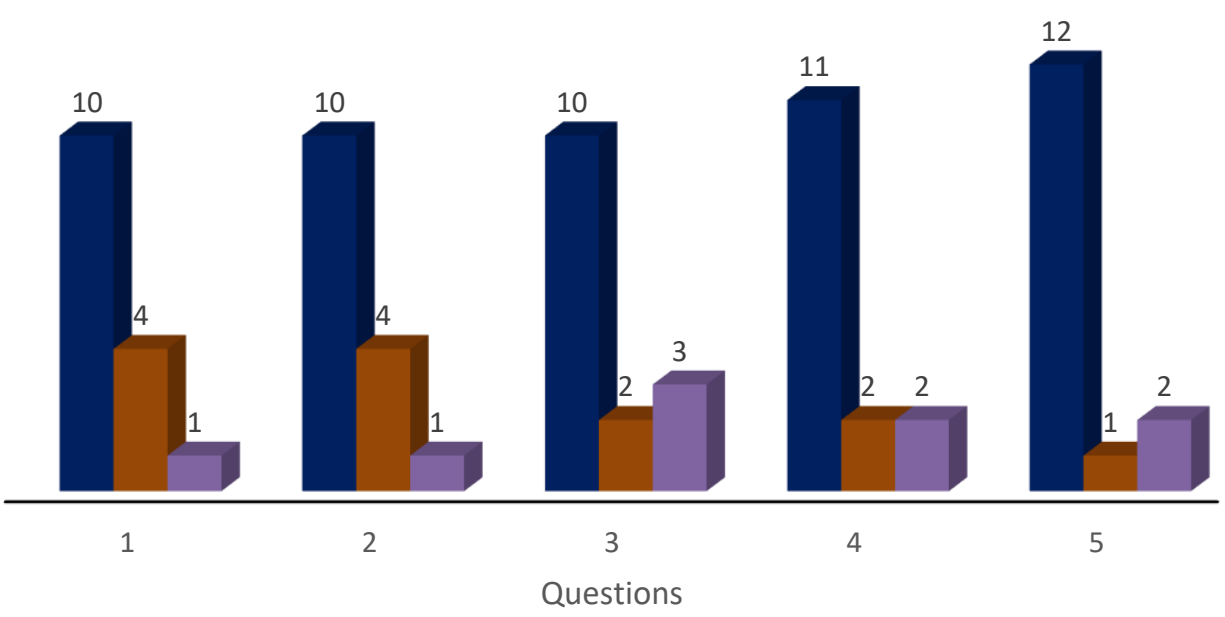

FIGURE 2. Pretest Results of Percent Composition by Mass Concept

There are also 5 questions about percent composition by mass concept in the form of four-tier diagnostic test format which is the same as in the molar mass concept. Figure 2 shows that there are 10 
students hold misconceptions (M), 4 students have understood the concept $(U)$, and 1 student did not understand the concept (DU) in answering question number 1 and 2 . For question number 3 , there are 10 students hold misconceptions (M), 2 students have understood the concept (U), and 3 students did not understand the concept (DU). For question number 4, there are 11 students who hold misconceptions (M), 2 students have understood the concept (U), and 2 students did not understand the concept (DU). While for question 5, there are 12 students hold misconceptions (M), 1 student has understood the concept (U), and 2 students did not understand the concept (DU). Generally, the number of students who have understood this concept are many more than the first concept, while the number of students who hold misconceptions is less more than the first concept.

\section{Limiting Reactant Pretest Results}

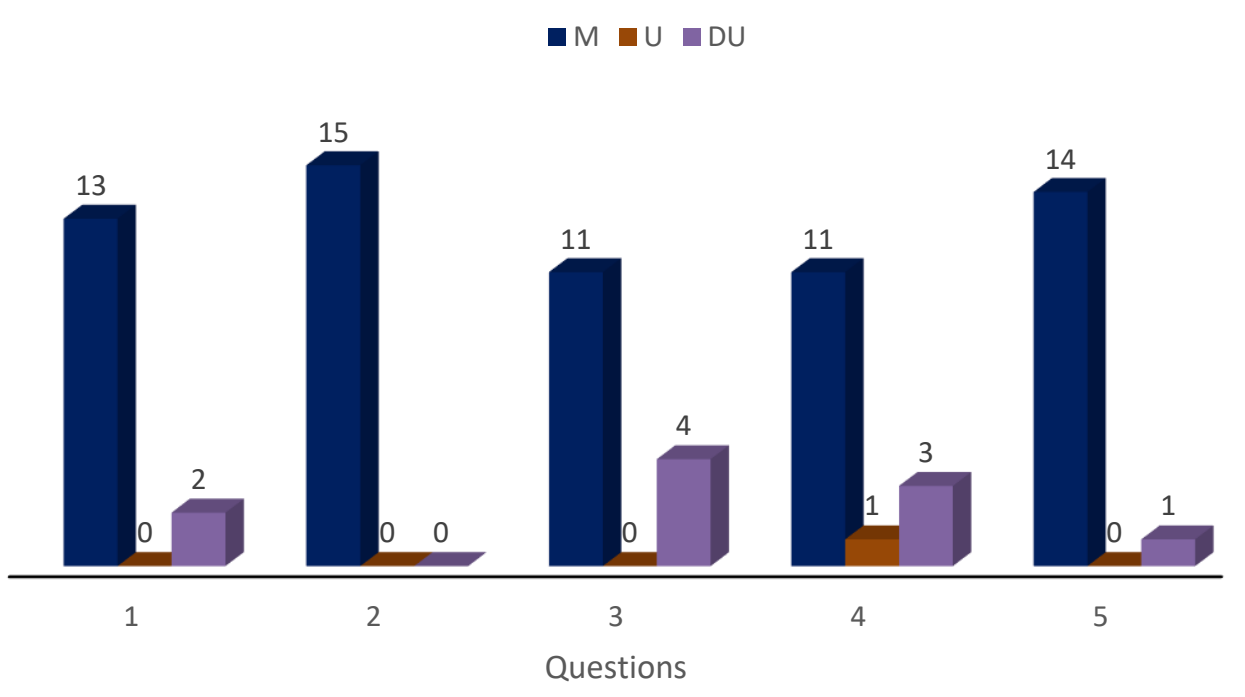

FIGURE 3. Pretest Results of Limiting Reactant Concept

There are also 5 questions about limiting reactant concept in the form of four-tier diagnostic test format, which is the same as in both concepts. Figure 3 shows that there are 13 students hold misconceptions $(\mathrm{M})$, no one has understood the concept $(U)$, and 2 students did not understand the concept (DU). All of the students hold misconceptions $(M)$ in answering question number 2 . For question number 3 , there are 11 students hold misconceptions (M), no one has understood the concept (U), and 4 students did not understand the concept (DU). For question number 4, there are 11 students hold misconceptions (M), 1 student has understood the concept $(\mathrm{U})$, and 3 students did not understand the concept (DU). While for question number 5 , there are 14 students who hold misconceptions $(\mathrm{M})$, no one has understood the concept (U), and 1 student did not understand the concept (DU). Based on the data, the number of students who have understood the concept was less than both concepts before. It means that many students hold misconceptions and do not understand this concept.

Students identified misconception and did not understand the concept have to pass the reduction part based on CCT strategy. There are four stages in CCT strategy, first showing the initial conception, second making cognitive conflicts, third making equilibration condition, fourth reconstructing the new concept [15]. In the first stage, students have presented their diagnostic test results. Then in the second stage, students have presented the statements that may be suitable for their misconceptions. If students believed that it is the true statement, they would be presented the right explanation about these statements. In the third stage consists of a complete explanation of molar mass concept, while the fourth stage consists of questions based on the explanation in the third stage to construct their new concept. After passing all of the stages, students are asked to do posttest for knowing their conception changes. It was the conception shift data that used to determine the effectiveness of the software. This data can be seen in Table 3 to Table 5. 
TABLE 3. Conception Shift Results of Molar Mass Concept

\begin{tabular}{ccccccc}
\hline \multirow{2}{*}{ No } & \multirow{2}{*}{ Conception Shifts } & \multicolumn{7}{c}{ Question Number } \\
\cline { 2 - 6 } & $\mathbf{1}$ & $\mathbf{2}$ & $\mathbf{3}$ & $\mathbf{4}$ & $\mathbf{5}$ \\
\hline 1 & M - U & 11 & 10 & 11 & 11 & 11 \\
2 & M - DU & 0 & 0 & 0 & 1 & 0 \\
3 & M - M & 4 & 2 & 4 & 1 & 4 \\
4 & D - U & 0 & 0 & 0 & 1 & 0 \\
5 & DU - DU & 0 & 0 & 0 & 0 & 0 \\
6 & DU - M & 0 & 1 & 0 & 0 & 0 \\
7 & U - U & 0 & 2 & 0 & 1 & 0 \\
\hline
\end{tabular}

Table 3 shows 11 students out of 15 students who hold misconceptions shifted to the understanding concept (M-U) while the other 4 students did not experience concept shifts (M-M). The percentage of $\mathrm{M}$ $\mathrm{U}$ shift in the first number is $73,33 \%$. For question number 2, 10 students out of 12 students who hold misconceptions shifted to the understanding concept (M-U) while the other 2 students did not hold concept shifts (M-M). The percentage of $\mathrm{M}-\mathrm{U}$ shift in the second question is $83,33 \%$. For question number 3, 11 students out of 15 students who hold misconceptions shifted to the understanding concept (M-U) while the other 4 students did not hold concept shifts (M-M). The percentage of M-U shift in the third question is $73,33 \%$. For question number 4,11 students out of 13 students who hold misconceptions shifted to the understanding concept (M-U), 1 student shifted to did not understand the concept (M-DU). In contrast, the other 1 student did not hold concept shifts (M-M). In this question, there was 1 student did not understand the concept in answering pretest then it has shifted to understand the concept (DU-U). The percentage of $\mathrm{M}-\mathrm{U}$ shift in the fourth question is $84,62 \%$. For question number 5 , 11 out of 15 students who hold misconceptions shifted to understanding concept (M-U) while the other 4 students did not hold concept shifts (M-M). The percentage of $M-U$ shift in the fifth question is $73,33 \%$. Thus, the average percentage of $\mathrm{M}-\mathrm{U}$ shift in the molar mass concept is $77,59 \%$. It means that software is categorized as effective for detecting and reducing misconceptions in molar mass concept.

TABLE 4. Conception Shift Results of Percent Composition by Mass Concept

\begin{tabular}{ccccccc}
\hline \multirow{2}{*}{ No } & \multirow{2}{*}{ Conception Shifts } & $\mathbf{1}$ & $\mathbf{2}$ & $\mathbf{3}$ & $\mathbf{4}$ & $\mathbf{5}$ \\
\hline 1 & M - U & 7 & 7 & 7 & 8 & 11 \\
2 & M - DU & 0 & 0 & 1 & 0 & 0 \\
3 & M - M & 3 & 3 & 2 & 3 & 1 \\
4 & DU - U & 0 & 1 & 1 & 2 & 1 \\
5 & D - DU & 1 & 0 & 1 & 0 & 0 \\
6 & DU - M & 0 & 0 & 1 & 0 & 1 \\
7 & U - U & 4 & 4 & 2 & 2 & 1 \\
\hline
\end{tabular}

Table 4 shows that 7 students out of 10 students who hold misconceptions shifted to an understanding concept (M-U) while the other 3 students did not hold concept shifts (M-M). The percentage of $M-U$ shift in the first question is $63,64 \%$. For question number 2, 7 students out of 10 students who hold misconceptions shifted to an understanding concept $(\mathrm{M}-\mathrm{U})$ while the other 3 students did not hold concept shifts (M-M). The percentage of $\mathrm{M}-\mathrm{U}$ shift in the second question is $63,64 \%$. For question number 3 , there were 7 students out of 10 students who hold misconceptions shifted to an understanding concept (M-U), 1 student shifted to did not understand the concept (M-DU), while the other 2 students did not hold concept shifts (M-M). The percentage of $\mathrm{M}-\mathrm{U}$ shift in the third question is $70 \%$. For question number 4 , there were 8 students out of 11 students who hold misconceptions shifted to an understanding concept $(\mathrm{M}-\mathrm{U})$ while the other 3 students did not hold concept shifts (M-M). The percentage of $\mathrm{M}-\mathrm{U}$ shift in the fourth question is $66,67 \%$. For question number 5,11 students out of 12 students who hold misconceptions shifted to an understanding concept (M-U) while the other 1 student did not hold concept shifts (M-M). The percentage of $\mathrm{M}-\mathrm{U}$ shift in the fifth question is $91,67 \%$. So, the average percentage of $\mathrm{M}-\mathrm{U}$ shift in percent composition by mass concept is $71,12 \%$. It means that software is categorized as effective for detecting and reducing misconceptions in percent composition by the mass concept. 
TABLE 5. Conception Shift Results of Limiting Reactant Concept

\begin{tabular}{|c|c|c|c|c|c|c|}
\hline \multirow{2}{*}{ No } & \multirow{2}{*}{ Conception Shifts } & \multicolumn{5}{|c|}{ Question Number } \\
\hline & & 1 & 2 & 3 & 4 & 5 \\
\hline 1 & $M-U$ & 12 & 14 & 9 & 10 & 14 \\
\hline 2 & $M-D U$ & 0 & 0 & 1 & 1 & 0 \\
\hline 3 & $M-M$ & 1 & 1 & 1 & 0 & 0 \\
\hline 4 & $D U-U$ & 1 & 0 & 4 & 3 & 0 \\
\hline 5 & $D U-D U$ & 0 & 0 & 0 & 0 & 0 \\
\hline 6 & $D U-M$ & 1 & 0 & 0 & 0 & 1 \\
\hline 7 & $U-U$ & 0 & 0 & 0 & 1 & 0 \\
\hline
\end{tabular}

Table 5 shows 12 students out of 13 students who hold misconceptions shifted to an understanding concept (M-U) while the other 1 student did not hold concept shifts (M-M). The percentage of $M-U$ shift in the first question is $92,31 \%$. For question number 2, 14 students out of 15 students who hold misconceptions shifted to an understanding concept $(\mathrm{M}-\mathrm{U})$ while the other 1 student did not experience concept shifts (M-M). The percentage of $M-U$ shift is the second question is $93,33 \%$. For question number 3 , there were 9 students out of 11 students who hold misconceptions shifted to an understanding concept (M-U), 1 student shifted to did not understand the concept (M-DU). In contrast, the other 1 student did not experience concept shifts (M-M). The percentage of $\mathrm{M}-\mathrm{U}$ shift in the third question is $81,82 \%$. For question number 4, 10 students out of 11 students who hold misconceptions shifted to an understanding concept $(\mathrm{M}-\mathrm{U})$ while the other 1 student shifted to did not understand the concept (M-DU). The percentage of M-U shift in the fourth question is $90,91 \%$. For question number 5,14 students out of 14 students who hold misconceptions shifted to an understanding concept (M-U). It means that all of the students who hold misconceptions in this question shifted to understand the concept; therefore, the percentage $\mathrm{M}-\mathrm{U}$ shift in the fifth question is $100 \%$. The average percentage of $\mathrm{M}-\mathrm{U}$ shift in limiting reactant concept is $91,67 \%$. It means that software is categorized as very effective to detect and reduce misconceptions in limiting reactant concept.

According to the conception shifts, the average percentage of $\mathrm{M}-\mathrm{U}$ shift in limiting reactant concept is the biggest one. It is caused by the animation presented in the third stage of CCT part to help students in understanding the abstract concept. The animation is used to explain the abstract material [17]. Whereas in the molar mass and percent composition concept, most of the information is explained in texts. The information is better presented in both pictures and texts because it can make students understand the concept more easily than presented only. Thus, the average percentage of $M-U$ shift in stoichiometry material is $80,13 \%$. This percentage is in the range of $61 \%-81 \%$ with the effective category. So that it means that software is categorized as effective to be used to detect and reduce misconceptions in stoichiometry material.

\section{CONCLUSION}

Based on the results of this study, software named Stoichiometry Reconstruction is categorized as effective to detect and reduce misconceptions in stoichiometry material. It is proved by the average percentage of $\mathrm{M}-\mathrm{U}$ shift about $80,13 \%$ which is in the range of $61 \%-81 \%$ with the effective category. This percentage is obtained from the average $\mathrm{M}$ - $U$ shift percentage of each concept that is $77,59 \%$ in the molar mass concept, $71,12 \%$ in the percent composition by mass concept, and $90,67 \%$ in the limiting reactant concept.

\section{REFERENCES}

1. Talanquer and Vicente. International Journal of Science Education. 33 (2) (2011).

2. Susilaningsih, Nuswowati, and Natasukma. IOP Conference Series: Materials Science and Engineering. (830) (2020).

3. M. Ibrahim, Konsep, Miskonsepsi, dan Cara Pembelajarannya, (Unesa Press, Surabaya, 2012).

4. F. Astuti, T. Redjeki, and N. D. Nurhayati. Jurnal Pendidikan Kimia (JPK). 5 (2) (2016).

5. Y. Ariyastuti and F. Yuliawati. Jurnal Pendidikan Sekolah Dasar. 4 (1) (2017).

6. D. Rositasari, N. Saridewi, and S. Agung. Edusains. 4 (2) (2014).

7. R. G. Aini, S. Ibnu, and E. Budiasih. Jurnal Pembelajaran Kimia (J-PEK). 1 (2) (2016). 
8. F. N. Sholihat, A. Samsudin, and M. G. Nugraha. Jurnal Penelitian \& Pengembangan Pendidikan Fisika. 3 (2) (2017).

9. D. K. Gurel, A. Eryilmaz, and L. C. McDermott. Eurasia Journal of Mathematics, Science \& Technology Education. 11 (5) (2015).

10. Tumanggor, Supahar, Kuswanto, and Ringo. Journal of Physics: Conference Series. (1440) (2020).

11. Q. Fariyani, A. Rusilowati. Sugianto. Journal of Innovative Science Education. 1 (2) (2012).

12. D. McKenna. Education and Human Development Master's Theses. 5 (2) (2014).

13. R. E. Slavin, Psikologi Pendidikan: Teori dan Praktik, (PT. Indeks, Jakarta, 2011).

14. Sugiyono, Metode Penelitian Kuantitatif dan $R \& D$, (Alfabeta, Bandung, 2011).

15. G. E. Wulandari and Sukarmin. Advances in Engineering Research. 171 (2018)

16. Ridwan and Sunarto, Statistika Untuk Penelitian, (Alfabeta, Bandung, 2012).

17. R. Adji and Sukarmin. Unesa Journal of Chemical Education. 2 (2) (2013). 